\title{
Relationship between Mean Free Path and Leaf Area in Boreal Forest Canopies
}

\author{
Emmanuel R. G. Abraham*1, Hayato Tsuzuki*2 and Tatsuo Sweda*2
}

\begin{abstract}
The free (unobstructed) sight through the foliage layer of forest canopy is expected to depend on the density of the foliage, i.e. dense foliage shortens the free sight while sparse one extends it. Conversely, it is possible to estimate foliage density from the free sight. Furthermore, it is possible to estimate from the free sight the amount of leaves in terms of leaf area or leaf area index (LAI) as a product of estimated foliage density and the thickness of the foliage layer. This paper presents a simple theory of estimating LAI from the free sight along with its verification using a set of field data from boreal forest of Canada. Free sight through the canopy was measured using airborne laser altimetry (ALA). Laser beams emitted vertically from an aircraft are reflected from different layers of the canopy, ranging from the uppermost canopy surface to the ground. The distance that a laser beam travels unimpeded into the canopy was assumed to be the free sight or more aptly, the free path, and the mean of a number of penetrations within the canopy as a good measure of the amount of leaf area. We assembled a set of field leaf area and mean free path data for 13 boreal forest sites in central Alberta, Canada. We related leaf area density with mean free path and found an inverse relationship between them. Furthermore, we verified that LAI can be estimated as a product of mean free path-based leaf area density and an estimate of canopy depth $(D)$ obtained based on the relationships we found between $D$ and mean tree height $(H)$ and between $\mathrm{H}$ and mean laser vegetation height.
\end{abstract}

Keywords: Airborne laser altimetry, boreal forest, mean free path, leaf area density, leaf area index

\section{INTRODUCTION}

Leaves serve as the primary interface between forest ecosystems and the atmosphere, serving both as solar energy collectors and as exchanger for gases. Models that are used for calculating radiant energy interception by canopies require information on amount of leaf area per unit of ground (leaf area index, LAI) and angle distribution; while models for the turbulent exchanges of heat and mass, and calculations of size

${ }^{* 1}$ Makiling Center for Mountain Ecosystems, College of Forestry and Natural Resources, University of the Philippines Los Banos, College, 4031 Philippines.

Phone/Fax: +63-49-536-3572;

email: eabraham@laguna.net

*2 The United Graduate School of Agricultural Sciences, Ehime University, 3-5-7 Tarumi,

Matsuyama, 790 Japan.

Phone/Fax: +81-89-946-9878 of penumbra also require a knowledge of the vertical distribution of leaf area within the canopy (CAMPBELL and Norman, 1989). Leaf area index is therefore an important variable for climate and ecosystem studies and is one of the vital boundary conditions fed to general circulation models for projecting global warming (TRENBERTH, 1992; MABUCHI, 2000).

Direct measurement of leaf area and its distribution within forest canopies is very difficult and time consuming. Although methods have been developed to directly and indirectly measure LAI on the ground (CHASON et al., 1991; Cutini et al., 1998; FASSACHT et al., 1994; GowER et al., 1999), expanding such estimates over extensive areas (e.g. to a regional scale) is still a major challenge and relies heavily on the use of remote sensing products.

Conventional methods of large-scale LAI measurement generally involve the comparison of vegetation indices developed from reflectance data obtained using optical sensors to in-situ measurements of LAI, but not a single vegetation index seem to be equally effective in relating with it (CAMPBELL, 1996). Airborne laser altimetry (ALA) remote sensing, however, is emerging as a potentially powerful tool in forest 
inventory and mapping (LEFSKY et al., 2001) and in estimating LAI over extensive areas (KuSAKABE $e t$ al., 2000; SASAKI $e t$ al., 2001).

ALA systems have three basic components: an infrared laser altimeter (ILA), a global positioning system (GPS), and an inertial navigation system (INS) mounted on an aircraft. The ILA emits infrared laser beams at a high frequency $(100-$ $20,000 \mathrm{~Hz}$ ) and records the time difference between laser pulse emission and reception of the reflected signal. The GPS continuously monitor the three-dimensional position of the aircraft whose orientation is controlled and determined by the INS. The round trip travel time of the laser beam multiplied by the speed of light equals twice the distance from aircraft to the target. The distance data is processed together with GPS and INS data to obtain the three-dimensional position of the objects that reflected the laser beams, that in the case of forests, could be the uppermost canopy surface or the ground in two extremes, or canopy elements in between (Fig. 1).

ALA systems currently employed in forest applications could be grouped into two. First are those that employ lowaltitude, small $(<1 \mathrm{~m})$ footprint (size of ground illuminated by the laser beam), range-only pulsed laser systems, with high repetition rates $(2,000-20,000 \mathrm{~Hz})$ that can be configured to measure the first-return pulse or the last-return pulse on a vertical or scanning mode (AldRED and Bonnor, 1985; Magnussen and Boudewyn, 1998; Ritchie et al., 1993). The second group employs medium altitude, medium to large footprint $(5-25 \mathrm{~m})$ pulsed laser systems with lower repetition rates $(<100 \mathrm{~Hz})$ but are capable of digitizing the power of the entire return signal within a single footprint, resulting in a waveform that records the vertical distribution of laser reflections (Blair and Hofton, 1999; Blair et al., 1999; Means et al., 1999; LeFsKY et al., 1997, 1999).

While studies on the application of the latter type of sensors to predict LAI has been undertaken (e.g. LeFsky et al., 1997), we are not aware of any that uses first-return altimetry data to directly estimate LAI in forest canopies. KusAKABE $e t$ al. (2000) for example, obtained LAI estimates from ALA data but did it indirectly using LAI's correlation with stand stocking and the latter's correlation with the area under the laser vegetation canopy height profile as established by Tsuzuki et al. (1998).

First-return ALA, however, is a potentially powerful tool to measure leaf area and its distribution within forest canopies. The area density of leaves (leaf area density, $A$ ) and the thickness of the foliage layer (i.e. canopy depth, $D$ ) basically determines the total amount of leaf area. The density is expected to influence the length of free (unobstructed) sight in such a way that dense foliage shortens the free sight while sparse one extends it. Conversely, it is possible to estimate foliage density from the free sight. Furthermore, it is possible to estimate from the free sight the amount of leaves in terms of leaf area or LAI as a product of estimated $A$ and $D$. Here, the advantage of first-return laser altimetry comes into play. With only one recorded reflection, a vertically emitted beam that

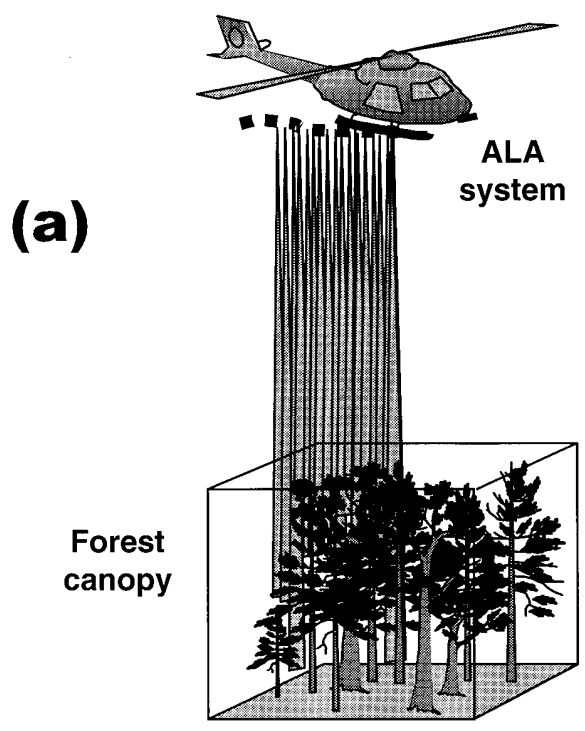

(b)

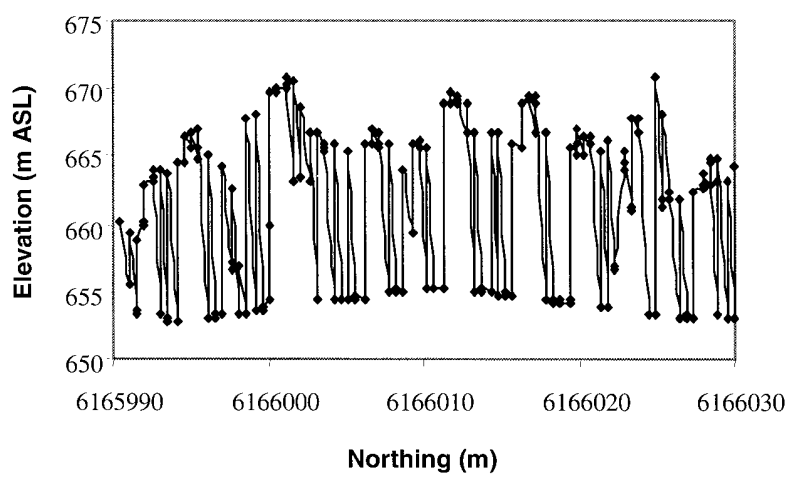

Fig. 1. Airborne laser altimetry remote sensing of vegetation height profiles. (a) The system uses a small footprint, ranging laser to continuously measure the vertical distance between the aircraft and reflecting objects while a GPS component measure the three-dimensional position of the aircraft. Post flight processing generates the three-dimensional position of reflecting objects along a flight course. (b) Shows a typical profile showing that beams are reflected from various levels of the canopy.

penetrates the canopy from above and travels for a certain distance before it hits foliage and is reflected back is tantamount to the free sight and could be termed as the free path. Obtaining the mean free path within a laser profiling segment using a number of within-canopy penetrations should then provide a good measure of the amount of leaf area.

This paper presents a simple theory of estimating LAI from the free sight - obtainable using ALA - along with its verification using a set of field data. We assembled a set of field leaf area and mean free path data for 13 boreal forest sites in northern Alberta, Canada. We related leaf area density with 
mean free path and found an inverse relationship between them. We further verified that LAI can be estimated as a product of mean free path-based leaf area density estimate and an estimate of $D$ obtained based on the relationship we established between $D$ and mean tree height $(H)$ and between $H$ and mean canopy height also obtained via laser altimetry.

\section{MATERIALS AND METHODS}

\section{Theoretical Basis}

Suppose a forest canopy layer in which leaves of exactly the same leaf area $a$ are distributed randomly with mean inclination angle $\theta$ as measured as dip from a horizontal plane. Suppose also that $N$ leaves are packed in a unit space of the canopy, i.e. at leaf density of $N$ so that the vertical mean free sight through the foliage layer would be $l$. Then, the probability of the vertical free sight being obstructed by going a minute distance $d x$ can be expressed in two different ways.

Since the unobstructed sight on an average is $l$ according to the assumption, the first expression of the probability is given by

$$
d x / l
$$

On the other hand, the expected number of leaves appearing in going a distance $d x$ in unit area perpendicular to the direction of sight is

$$
N d x
$$

posing an obstruction area of

$$
N a \cos \theta d x
$$

where $a \cos \theta$ represents an effective obstruction area each leaf contributes. Being the proportion of sight obstructing area, (2) is another expression of the probability of the sight being obstructed in $d x$. Thus, equating (1) and (2), we get

$$
l=\frac{1}{N a \cos \theta}
$$

By substituting $1 / \cos \theta$ by another constant $c$,

$$
l=\frac{c}{N a}
$$

results, which signifies that the mean free sight is inversely proportional to leaf area density $\mathrm{Na}$, i.e. leaf area in unit space. Our interest is to estimate leaf area density from the mean free sight, and thus by transposing the above equation we get

$$
N a=\frac{c}{l}
$$

Substituting $N a$ with a single variable $A$ for leaf area density, we finally get

$$
A=N a=\frac{c}{l}
$$

By introducing yet another variable $D$ to represent canopy thickness or depth, Eq. (3) can be converted to one relating the mean free sight to the most common indicator of leaf amount, leaf area index $I$, i.e. the total leaf area per unit of ground as follows:

$$
I=A D=\frac{c}{l} D
$$

In application of the above theory to the reality of leaf area remote sensing using airborne laser altimetry, the term 'free sight' would be more aptly expressed as 'free path', i.e. the depth a laser beam penetrates into canopy without being obstructed by leaves. The more practical side of the difference between the free sight and free path is that while the sight is an imaginary line without thickness, the laser beam has a footprint of a certain size. This difference, however, only enlarges the collision area $a \cos \theta$ and accordingly makes $c$ smaller by a certain factor proportional to footprint size.

\section{Deduction of Mean Free Path from Laser Altimetry Data}

Laser penetration depth into forest canopy was acquired for 13 boreal forest sites in central Alberta, Canada (Fig. 2) over which a laser profiling mission was flown in September 1997 using a helicopter-borne vertical first-return ALA system. The original ALA data consisted of a series of clearance measurements between the aircraft and whatever the objects on the ground reflecting the laser beam. Incorporating the flight altitude data continuously monitored by the airborne GPS simultaneously with laser profiling, the original data were calibrated into a surface profile consisting of reflections from the ground objects. For each study site, individual components of the surface profile were classified into three categories. They are the reflections from (1) the ground itself, (2) the uppermost canopy surface, and (3) within the canopy layer. Then from the respective set of ground hits and of canopy hits above, a continuous topographic profile and a canopy profile were generated using cubic spline interpolation.

Subsequently using these two different profiles representing topography and vegetation profile, two measures characterizing each study site was compiled. One is the ALAbased canopy height calculated as the difference between the individual canopy hits and the corresponding topographic surface. They were then averaged as an estimated mean 
canopy height $\left(H_{\text {est }}\right)$ for each study site for comparison with the observed counterpart $\left(H_{o b s}\right)$. As shown in Fig. 3 they were well correlated, confirming the capability of airborne laser altimetry to measure vegetation height effectively and accurately.

The other stand measure compiled was the free path or the depth of laser penetration into the canopy. It was calculated as a difference between the canopy profile and individual reflections from within the canopy. They were then averaged for each study site to obtain the mean free path $(l)$,

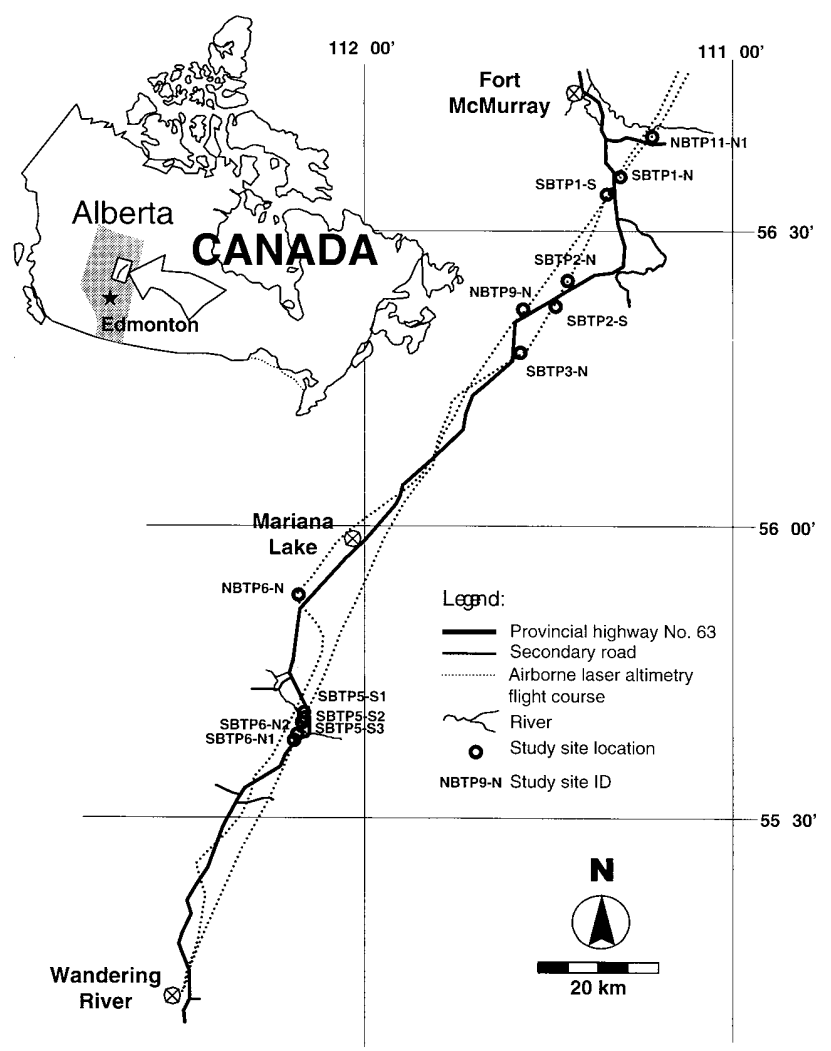

Fig. 2. Location of study sites

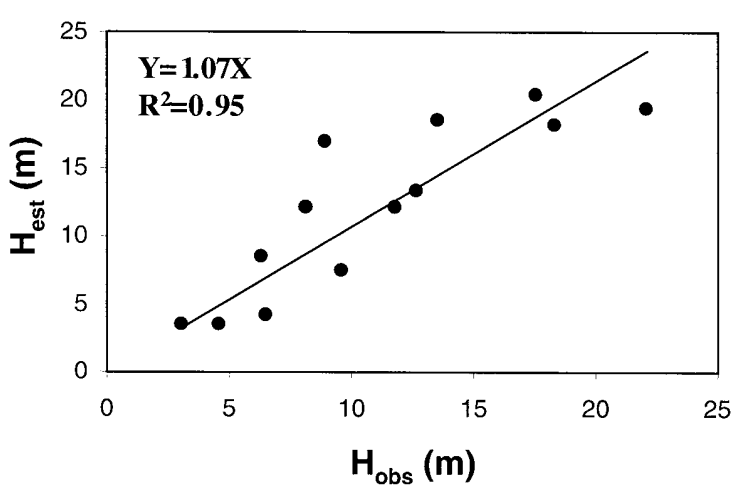

Fig. 3. Relationship between observed mean tree height $\left(H_{o b s}\right)$ and mean tree height estimated via laser altimetry $\left(H_{\text {est }}\right)$ the principal subject of the present paper, for estimating the leaf area density and leaf are index in the subsequent analyses.

Ground Measurement of Leaf Area Density and Leaf Area Index

To obtain actual leaf area density $\left(A_{o b s}\right)$ and leaf area index $\left(I_{o b s}\right)$, ground truthing surveys were conducted in August and September 1999 for the 13 plots co-located with the ALA profiling segments. Plot size varied in accordance with the average size of constituent trees, i.e. plot length and plot width as twice the average tree height and crown diameter, respectively. In each plot, the species and, diameter at breast height $(d b h)$ of all the trees exceeding breast height $(1.3 \mathrm{~m})$ were inventoried. Then a total of 33 trees were harvested from ten of the study sites to establish regressions of tree height, crown length, crown volume and leaf area on $d b h$. These sample trees represented four boreal species, namely black spruce (Picea mariana (Mill.) BSP), white spruce (Picea glauca (Moench) Voss), jack pine (Pinus banksiana Lamb.) and trembling aspen (Populus tremuloides Michx.). Based on the theory of allometry (AвRAHAm et al., in review), a set of regression equations were developed to relate $d b h$ with tree height, crown length and crown volume, and then applied to the censused $d b h$ measurement to obtain these measures for all the trees in each study plot. These individual measures were then averaged or summed up to obtain observed mean canopy height $\left(H_{o b s}\right)$, mean crown depth $\left(D_{o b s}\right)$ and total canopy volume (V).

As pointed out earlier, $D$ in Eq. (4) is a crucial variable along with mean free path $(l)$ for estimating leaf area index using airborne laser altimetry. While $H$ can readily be estimated by laser altimetry, such is not the case with $D$. However, as shown in Fig. $4, D_{o b s}$ was found to be well correlated with $H_{o b s}$, indicating that a laser-based estimate of canopy depth $\left(D_{e s t}\right)$ can be obtained from $H_{e s t}$ using the coefficient obtained from regression of $D_{o b s}$ on $H_{o b s}$.

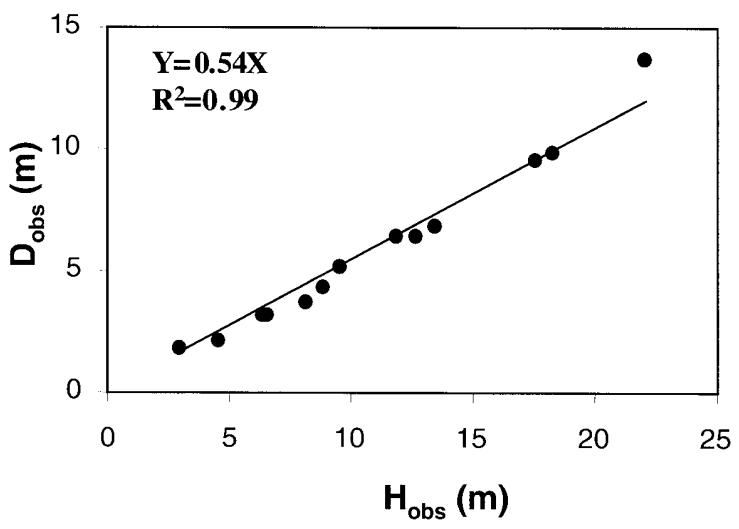

Fig.e 4. Relationship between observed mean tree height $\left(H_{o b s}\right)$ and observed mean canopy depth $\left(D_{o b s}\right)$ 
Leaf area in individual trees was obtained from leaf weight using the ratio of leaf area to leaf weight in sample leaves. The sample leaves were obtained from the upper, middle and lower crown of the harvested trees. Leaf areas of samples were measured using an image processing program 'NIH Image' Version 1.61 (Wayne Rasband, National Institutes of Health, USA). In large trees, for which census measurement of leaves was impractical, foliage weight was estimated from branch diameter using a regression established between them. Plot leaf area was compiled as a sum of individual tree leaf area obtained from $d b h$ using allometric equations developed using the harvested trees. Leaf area thus obtained was converted to leaf area density $\left(A_{o b s}\right)$ and leaf area index $\left(I_{o b s}\right)$ for each plot by dividing them with canopy volume $(V)$. and projected canopy area $(G)$, respectively. Leaf area index $\left(I_{o b s}\right)$ was computed as a product of $A_{o b s}$ and $D_{o b s}$. The characteristics of the thirteen sites in terms of the aforementioned laser altimetry and ground truthing variables are summarized in Table 1.

\section{Validation of Theory}

The postulated theory of inverse proportionality of mean free path with leaf area density (Eq. (3)) and with leaf area index (Eq. (4)) was tested using $l, A_{o b s}$ and $I_{o b s}$. To begin with, Eq. (3) was tested by plotting $A_{o b s}$ against $l$ to see the sign of inverse proportionality between them. Then we related $A_{o b s}$ with $l$ in accordance with Eq. (3), in which non-linear regression was conducted using the statistical software JMP ver. 4.0 (SAS Institute, Inc., USA). The constant of proportionality $c$ determined in this process of fitting Eq. (3) can now be utilized for estimating leaf area index from the laser altimetry data in accordance with Eq. (4).

The expected relationship between leaf area index and mean free path (Eq. (4)) was tested $y$ examining the correspondence between observed leaf area index $\left(I_{o b s}\right)$ and its laserbased counterpart $\left(I_{\text {est }}\right)$ at three different levels corresponding to three different levels of ALA involvement in obtaining an estimate of leaf area index, i.e.

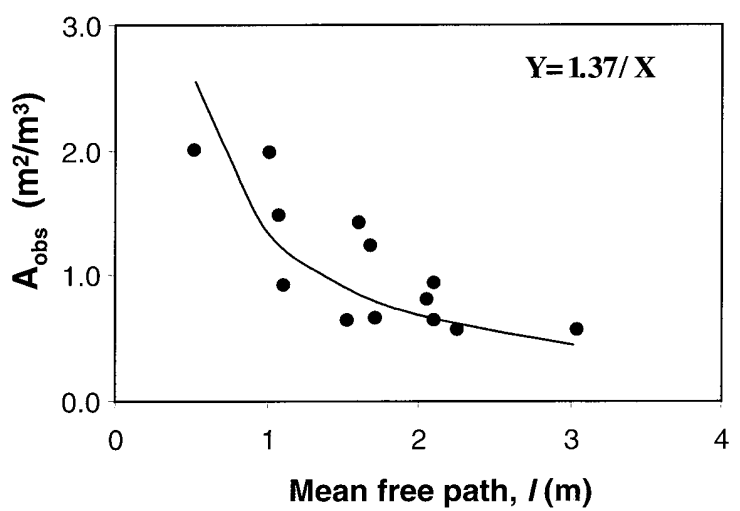

Fig. 5. Relationship between mean free path $(l)$ and observed leaf area density $\left(A_{o b s}\right)$

$$
\begin{aligned}
I^{\prime}{ }_{e s t} & =A_{e s t} D_{o b s}, \\
I^{\prime \prime}{ }^{\prime \prime s t} & =A_{o b s} D_{e s t}, \\
\text { and } & \\
I_{\text {est }} & =A_{\text {est }} D_{\text {est }} .
\end{aligned}
$$

In estimates (5) and (6), the airborne laser altimetry is only partially involved appearing in either one of the factors $A$ or $D$, whereas estimate (7) is fully ALA based.

\section{RESULTS AND DISCUSSION}

As shown in Fig. 5, leaf area density was found to be inversely proportional to the mean free path as had been expected from the proposed theory. The constant of proportionality $c$ obtained from regression was used to estimate leaf area density $\left(A_{e s t}\right)$ from the mean free path, which we plotted against $A_{o b s}$ in Fig. 6 . The figure shows that the estimated leaf area density $\left(A_{e s t}\right)$ approximates the observed counterpart reasonably well though it tends to underestimate the reality as indicated by the calculated constant of proportionality of 0.92 . With coefficient of determination $\left(\mathrm{R}^{2}\right)$ at 0.91 , the estimated leaf area density is also well correlated with the observation.

We also found close correspondence between observed leaf area index $\left(I_{o b s}\right)$ and its laser-based estimated counterpart $\left(I_{\text {est }}\right)$ at three different levels of comparison with varying degree of involvement of ALA-based $A$ and $D$ estimates. In the first level, where of the two factors determining leaf area index, i.e. leaf area density $(A)$ and canopy depth $(D)$, only the former is laser-based while observed values were used for the latter, the estimated leaf area index $\left(I_{\text {est }}^{\prime}\right)$ correlated well with observed $\left(R^{2}=0.93\right)$ as shown in Fig. 7. Again in this case, estimates tended to be less than observation with the constant of proportionality at 0.79 . The tendency of underestimation, however, was reduced in the second level of comparison where

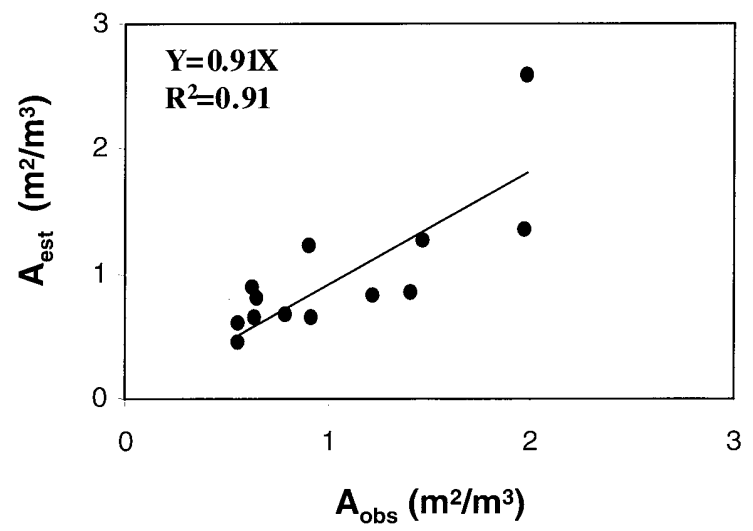

Fig. 6. Comparison of observed leaf area density $\left(A_{o b s}\right)$ with leaf area density estimated from mean free path $\left(A_{\text {est }}\right)$ 


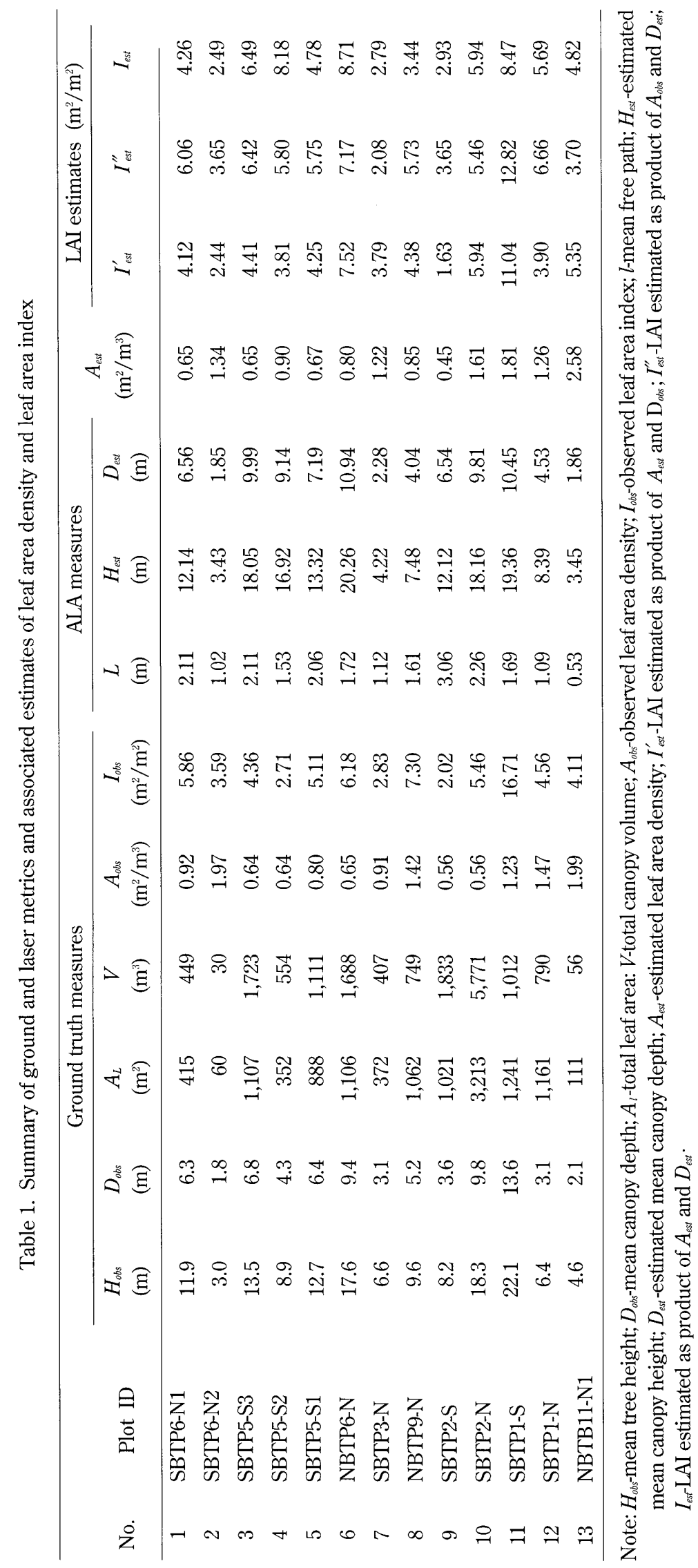




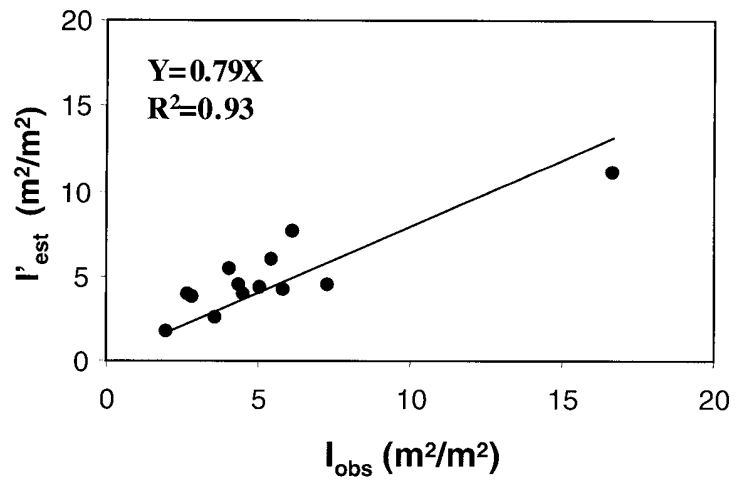

Fig. 7. Comparison of observed leaf area index $\left(I_{o b s}\right)$ with leaf area index estimated as product of estimated leaf area density $\left(A_{e s t}\right)$ and observed mean canopy depth $\left(D_{o b s}\right)$

laser-based estimate was used only for canopy depth as in Fig. 8. Here, the constant of proportionality rebounded to 0.93 indicating that estimates are closer to observed values than in the first level. In both levels however, the overall variability did not differ with $\mathrm{R}^{2}$ remaining at 0.93 in both cases. These results suggest that between $A_{\text {est }}$ and $D_{\text {est }}$, it is the latter that more closely approximates reality, i.e. laser-based estimates of $D$ tend to be closer to actual value than does laser-based estimates of $A$. The tendency of laser-based $A$ and $D$ to underestimate reality is compounded when both $A_{\text {est }}$ and $D_{\text {est }}$ are used to estimate leaf area index as found in the third level of comparison. Fig. 9 shows that when both laser-based variables are used, the constant of proportionality further reduces to 0.77 , along with increase in variability of estimates relative to observation indicated by $\mathrm{R}^{2}$ of 0.76 .

It is natural for the coefficient of determination to deteriorate with increasing involvement of laser-based factors in the estimates of leaf area density and leaf area index. On the other hand, the reason for the consistent trend of underestimation of leaf area density and leaf area index is not

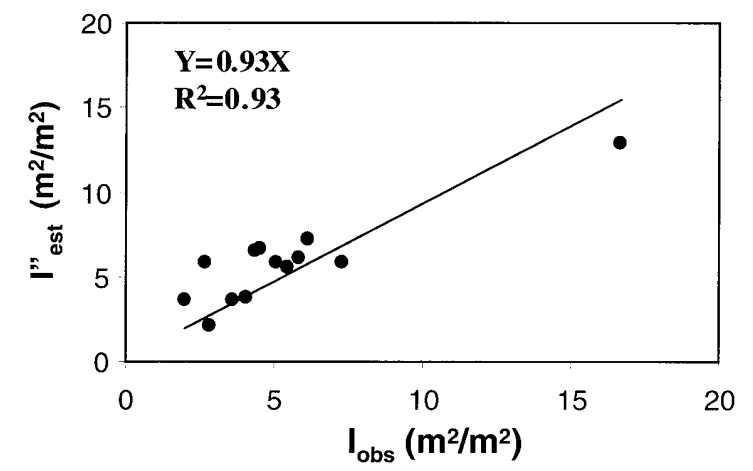

Fig. 8. Comparison of observed leaf area index $\left(I_{o b s}\right)$ with leaf area index estimated as product of observed leaf area density $\left(A_{o b s}\right)$ and estimated mean canopy depth $\left(D_{e s t}\right)$

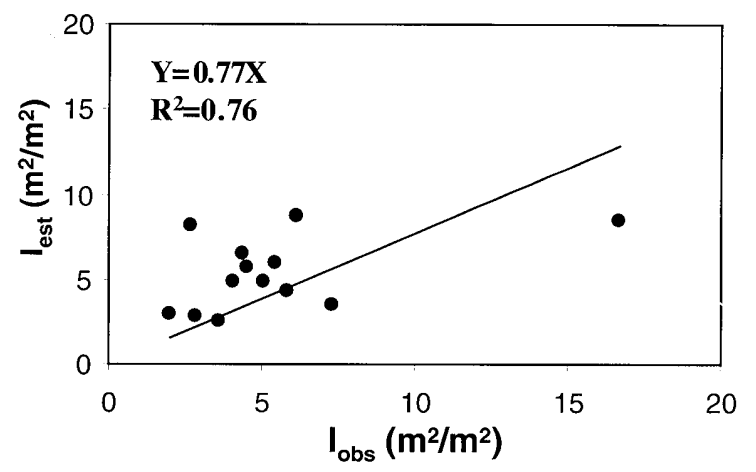

Fig. 9. Comparison of observed leaf area index $\left(I_{o b s}\right)$ with leaf area index estimated as product of estimated leaf area density $\left(A_{e s t}\right)$ and estimated mean canopy depth $\left(D_{\text {est }}\right)$

very clear. One possible cause is random fluctuation in our data set, which just happened to have worked in the way it did. Another possible cause may be the discrepancy between theory and reality that the laser beams may have been blocked by leaf clusters rather than by individual leaves as postulated in the theoretical derivation. At this stage of analysis, however, we are neither very sure if this is actually the case nor ready to give more exact explanation for the underestimation.

In spite of these shortcomings, it can be concluded that the estimates of leaf area density and leaf area index from airborne laser altimetry are reasonably good, especially in view of the fact that the airborne laser altimetry can cover several hundred kilometers in just a matter of a day.

The above results suggest the potential usefulness of our proposed theory in applying laser altimetry in estimating leaf area and leaf area index in boreal forest canopies. Airborne laser altimetry sensors that capture reflections for the whole vertical range of forest canopy within a single footprint are increasingly being used to study other measures of forest canopy structure than canopy heights (BLAIR and HofTon, 1999; Blatr et al., 1999, LefsKy et al., 1997; MEAns et al., 1999). On the other hand, the use of sensors that capture only the first return in each footprint is generally confined to measurement of vegetation height (e.g. Magnussen and Boudewyn, 1998; NiLson, 1996) or height along with height-related variables as stand stocking and biomass (e.g. NAESSET, 1997; NELSON et al., 1988). However, our results suggest that by applying mean free path theory, first-return laser altimetry data can effectively be used to estimate leaf area density and leaf area index over boreal forest canopies. To our knowledge, this is the first attempt of applying mean free path to estimate LAI in forest canopies using first-retun laser altimetry data and our results should reinforce current efforts to apply laser altimetry to measure LAI over extensive areas.

\section{CONCLUSION}

Our results verified the theory that the unobstructed sight 
(free path) through the foliage layer of boreal forest canopies depended on the density of foliage and that leaf area density was inversely proportional to the mean free path, making it possible to estimate the former from the latter. We also found it possible to estimate leaf area index as the product of leaf area density and canopy depth-both predictable from laser altimetry data.

\section{LITERATURE CITED}

Abraham, E .R. G., Kusakabe, T., Tsuzuki, H. and Sweda, T., (in review): Allometric relationship between leaf area and tree measures in selected boreal species in central Alberta, Canada. Can. J. For. Res.

AldRED, A. H. and BonNoR, G. M., (1985): Applications of airborne lasers to forest surveys. Can. For. Serv. Petawawa Natl. For. Inst. Inf. Rep. PI-X-51, 62pp

Blair, J. B. and Hofton, M. A., (1999): Modeling laser altimeter waveforms over complex vegetation using high-resolution elevation data. Geophysical Research Letters 26(16): 2509-2512

Blair, J. B., Rabine, D. L. and Hofton, M. A., (1999): The laser vegetation imaging sensor: a medium-altitude, digitisation-only, airborne laser altimeter for mapping vegetation and topography. ISPRS Journal of Photogrammetry and Remote Sensing 54:115-122

CAmpBell, J. B., (1996): Applications: Plant Sciences. In Introduction to Remote Sensing. $2^{\text {nd }}$ Edition. The Guilford Press, New York, $444-481$

Campbell, G. S. and Norman, J. M., (1989): The description and measurement of plant canopy structure. (In Russel, G.,Marshall, B. and Jarvis, P. G. (eds.): Plant canopies: their growth, form and function). Cambridge University Press, Cambridge, 1-19

Chason, J.W., Baldouchi, D. D. and Huston, M. A., (1991): A comparison of direct and indirect methods for estimating forest canopy leaf area. Agr. For. Meteor. 57:107-128

Cutini, A., Matteucci, G. and Mugnozza, G. S., (1998): Estimation of leaf area index with Li-Cor LAI 2000 in deciduous forests. Forest Ecology and Management 105:55-65

Fassnacht, K. S., Gower, S. T., Norman, J. M. and McMurtrie, R. E., (1994): A comparison of optical and direct methods for estimating foliage surface area index in forests. Agric. For. Meteorol. 71:183207

Feynman, R. P., Leighton, R. B. and Sands, M., (1963): The Feynman lectures on Physics. Volume 1, Addison Wesley Publishing Co., Massachusetts, USA, 43-1 - 43-4

Gower, S. T., Kucharik, C. J., and Norman, J. M., (1999): Direct and indirect estimation of leaf area index, fAPAR, and net primary production of terrestrial ecosystems. Remote Sens. Environ. 70:29-51

Kusakabe, T., Tsuzuki, H., Hughes, G. and Sweda, T., (2000): Extensive forest leaf area survey aiming at detection of vegetation change in subarctic-boreal zone. Polar Bioscience 13: 133-146

Lefsky, M. A., Cohen, W. B. and SpIEs, T. A., (2001): An evaluation of alternate remote sensing products for forest inventory, monitoring, and mapping of Douglas-fir forests in western Oregon. Can. J. For. Res. 31: 78-87

Lefsky, M. A., Cohen, W. G., Acker, S. A., Spies, T. A., Parker, G. G. and HARDING, D., (1997): Lidar remote sensing of forest canopy structure and related biophysical parameters at the H.J. Andrews Experimental Forest, Oregon, USA. (Greer, J. D. (ed.): Natural Resources Management using Remote Sensing and GIS), ASPRS, Washington D. C., 79-91

Lefsky, M. A., Harding, D., Cohen, W. B., Parker, G. and Shugart, H. H., (1999): Surface lidar remote sensing of basal area and biomass in deciduous forest of eastern Maryland, USA, Remote Sens. Environ. 67: 83-98.

MabUCHI, K., SATO, Y. and KIDA, H., (2000): Numerical study of the relationships between climate and the carbon dioxide cycle on a regional scale. Journal of the Meteorological Society of Japan 78(1):25-46

Magnussen, S. and Boudewyn, P., (1998): Derivations of stand heights from airborne laser scanner data with canopy-based quantile estimators. Can. J. For. Res. 28: 1016-1031

Means, J. E., Acker, S. A., Harding, D., Blair, J. B., Lefsky, M. A., Cohen, W. B., Harmon, M. E. and McKeE, W. A., (1999): Use of large-footprint scanning airborne lidar to estimate forest stand characteristics in the western cascades of Oregon. Remote Sens. Environ. 67: 298-308

NAESSET, E., (1997): Estimating timber volume of forest stands using airborne laser scanner data. Remote Sens. Environ. 61:246-253

Nelson, R., Krabill, W. and Tonelli, J., (1988): Estimating forest biomass and volume using airborne laser data. Remote Sens. Environ. 24: 247-267

NiLsson, M., (1996): Estimation of tree heights and stand volume using an airborne lidar system. Remote Sens. Environ. 65:1-7

Ritchie, J. C., Evans, D. L., Jacobs, D., EveritT, J. H., and Weltz, M. A., (1993): Measuring canopy structure with an airborne laser altimeter. Transactions of the ASAE, 36:1235-1238

SASAKI, N., TakejIma, K., KusaKabe, T. and Sweda, T., (2001): Forest cover classification using Landsat Thematic Mapper data for areal expansion of line LAI estimate generated through airborne laser profiler. Polar Bioscience 14:110-121

Schreir, H., Lougheed, J., Tucker, C. and Leckie, D., (1985): Automated measurements of terrain reflection and height variations using an airborne infrared laser system. Int. J. Remote Sensing 6(1): 101-113

Sweda, T., Yamamoto, T. and Shibayama, Z., (1998): Airborne infrared-laser altimetry of forest canopy profile for extensive and accurate assessment of timber resource and environmental functions of forests. In Proceedings: IUFRO International Symposium on Global Concerns for Forest Resource Utilization. $736-745$

Trenberth, K. E., (1992): Climate system modeling. Cambridge University Press, Cambridge, xxix $+788 \mathrm{pp}$

Tsuzuki, H., Abraham, E. R. G., Kusakabe, T., Yamamoto, T. and SwEDA, T., (1998): Timber cruising over extensive forest area with airborne laser altimeter. In Proceedings: IUFRO International Symposium on Global Concerns for Forest Resource Utilization. $746-754$

(Received 25 June 2001)

(Accepted 5 October 2001) 